\title{
A new method of evaluation of thermal parameters for textile materials
}

\author{
by M. Michalak ${ }^{1}$, M. Felczak ${ }^{2}$, B. Więcek ${ }^{2}$
}

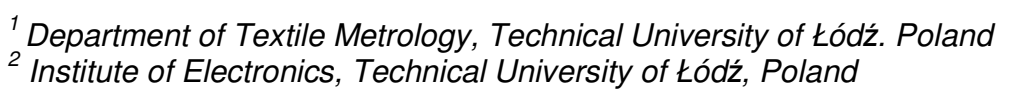

\section{Abstract}

A new method for evaluating the thermal conductivity of flat textile products, such as for example nonwovens with and without phase-change materials (PCM) is presented in this paper. It is based on optimization procedure which minimizes the temperature difference obtained from modeling and thermovision measurements on both sides of the investigated sample.

\section{Introduction}

Evaluation of thermal parameters of new smart textile materials becomes a difficult problem, especially if the materials are made of phase-change or temperature depended compounds. In the investigations presented in this paper, a method of simultaneous temperature measurement on both sides of the textile sample was used [17]. This approach is based on using two mirrors and the measured sample located in between them as shown in Fig.1. By measuring the temperature on both sides, one can evaluate the cross-sectional thermal conductivity of the material, which can differ from the longitudinal one.
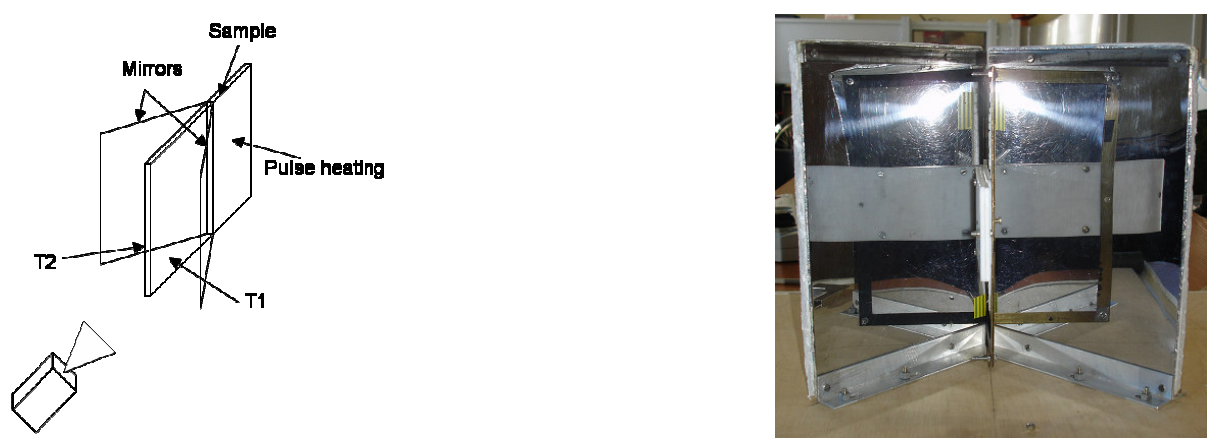

Fig. 1. Measurement stand with IR mirrors

The surface of one half of the sample was heated (Fig. 1). The heat flux flows towards non heated part of the sample reaching both sides. The values of temperature on both sides are slightly different, what is used to estimate the cross-sectional thermal conductivity. Two perpendicular mirrors are placed in front of the thermal camera. The static and dynamic thermal processes were recorded by the thermovision system and then processed using the dedicated software. In this work the preliminary investigations have been done. In order to verify the experimental setup, and correctness of the assumptions, the Teflon samples imitated textile products were used.

\section{Structure of the investigated sample}

A Teflon model of the textile material has a multilayer structure. The first and the longest layer has a thermal contact with the heater. The measured part consists of 3 layers (Fig. 2) that are located in between the mirrors.

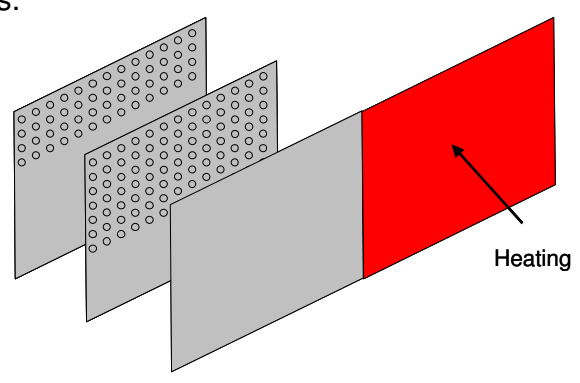

Fig. 2. External layer of the sample connected to the heater, middle and the second external one with holes imitating the porosity of the textile material

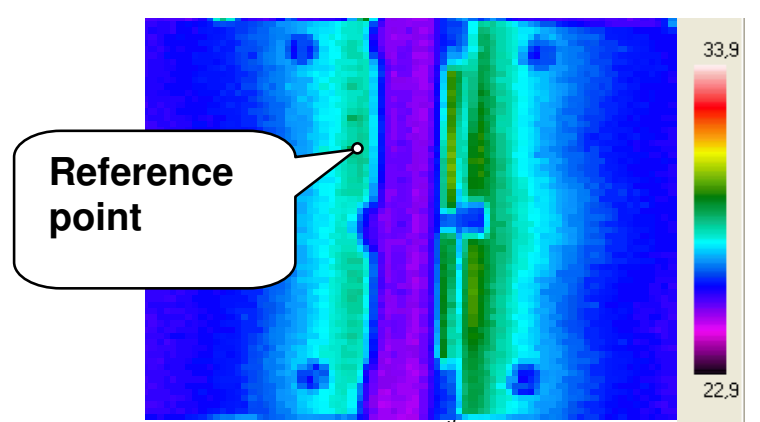

Fig. 3. Thermal image takes in $600^{\text {th }}$ second from the switching off the heating 
The heat flux flows from one side of the sample to opposite one and heats it up to the different values of the temperature. Typically, the heat is propagating along the textile material in different way than in the transversal direction, due to the anisotropy of the material properties.

In order to create the multilayer sample, 3 Teflon substrates of $3 \mathrm{~mm}$ thickness were firmly connected. For ensuring the textile material imitation, the holes were made in the middle and external layers to get the porosity similar as it exists in the real textiles (Fig. 2). The substrates were vertically positioned. The heated zone was outside of the region which was measured by the thermal camera. In the upper part of the sample, the holes were in 2 plates, while in the middle part, the only single layer had the holes, and the bottom one was without any hole in it. In between the plates there is a thin layer of air.

The heating was lasting 50s. After switching of the electrical power, the heating was still active for a few seconds due to the thermal inertia of the heater. The recording of thermal images was performed with 1 frame/s during 1000s. An exemplary thermal image excluded from the sequence at $t=600 \mathrm{~s}$ is presented in Fig. 3 . The reflected IR radiation forms the thermal image which shows the temperature difference on both sides of the material. The higher temperature is on the heated edge of the sample. In order to locate precisely the same measuring areas on different images and sequences, a small reference point was used to indicate the right position.

A nonwoven with phase change material (PCM) is going to be investigated in this research, and the results will be compared with a typical textile material. Both sides on the materials are intended to be investigated, both during heating or cooling process.

\section{Thermal conductivity evaluation by solving the inverse thermal problem}

The forward and inverse heat transfer problems were used to prepare a new approach for thermal parameter evaluation. To verify the proposed approach, a sample of rectangular shape with the width much smaller than its length was prepared (Fig. 5). A pulse of thermal energy was delivered to the material, and temperature distribution was calculated during heating and cooling, using $3 D$ thermal model - eqn. (1).

$$
\frac{\partial}{\partial x}\left(\lambda \frac{\partial T}{\partial x}\right)+\frac{\partial}{\partial y}\left(\lambda \frac{\partial T}{\partial y}\right)+\frac{\partial}{\partial z}\left(\lambda \frac{\partial T}{\partial z}\right)+q_{v}=c_{w} \rho \frac{\partial T}{\partial t}
$$

It was assumed that thermal conductivity is varying and depends on the direction in the material. Typically, the conductivity in cross-sectional direction is higher than in longitudinal one. In the forward problem, assuming the values for thermal conductivity $(\lambda)$, specific heat $\left(c_{w}\right)$ and density $(\rho)$, for a given power $(P)$ delivered for the sample, the temperature distribution $T=f(P)$ was calculated.

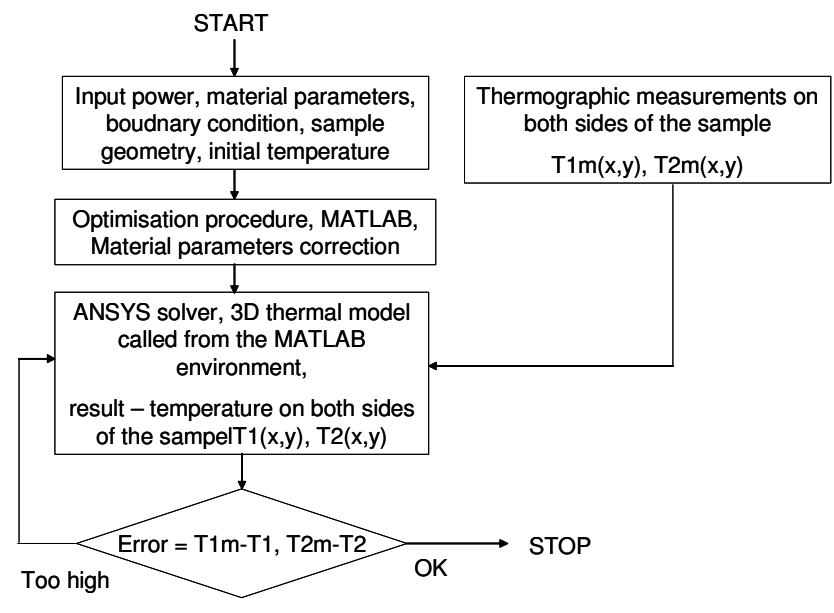

Fig. 4. Block diagram of the algorithm

Then, in the inverse problem, for a given power $P$ and measured temperature distribution on both sides of the sample $\rho, \lambda, c_{w}$ were evaluated. One assumed the boundary conditions for the thermal problem defined by the natural convection.

In order to solve the described problem, the optimization procedure (inverse problem) was applied using MATLAB® solver, including the thermal model of a sample prepared in ANSYS $\AA$ package (forward problem) Fig.4. The program in MATLAB called the ANSYS model in an iterative loop until the temperature values in the chosen places on the sample obtained from the calculations and measurements were matched with a small given error. 


\section{Experiments and the results}

At first, in order to evaluate the thermal parameters of a nonwoven, the thermal modeling was carried out for the materials with known thermal coefficients.

The investigations concerned the evaluation of thermal parameters, such as thermal conductivity and capacity of textile materials. In the research, one side of a nonwoven sample, which had a rectangular shape was heated (Fig. 5). The thermal process was transient, and the temperature evolution was measured by the thermographic camera. Temperature maps were captured on the both sides of the measured sample to evaluate the cross-sectional thermal conductivity. The simultaneous measurement on both sides was done using a set two mirrors and the measured material placed in between them. The presented investigations can be effectively used for evaluation of anisotropic, intelligent textile materials.

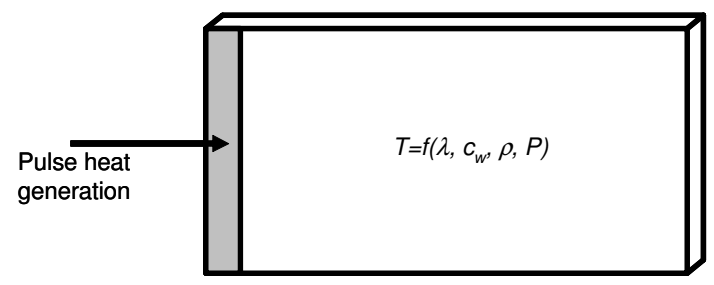

Fig. 5. A textile material sample heated on one side

For the first simulation of the forward problem, a Teflon sample with thermal conductivity $\lambda=0.259$ $\mathrm{W} /(\mathrm{m} \cdot \mathrm{K})$ was used. At the beginning, the power (heat flux) delivered to the sample during the experiment, was identified. For this evaluation the heat flux in the simulation was adjusted to get the same temperature as in the measurements. The thermal model (egn. 1) was being solved using ANSYS® software. As a result $T(x, y, z)=$ $f(Q)$ was obtained, where $Q$ - is a power density of the heat being delivered to the sample.

Then, in the inverse thermal problem, by taking the temperature values in the chosen points on both sides of the investigated material and using the optimisation procedure, unknown thermal conductivity of the textile material was calculated. 40 points, 20 on each side, were chosen for calculations. An initial value of thermal conductivity was taken from the range $0 \div 1000 \mathrm{~W} /(\mathrm{m} \cdot \mathrm{K})$. For each corresponding pair of temperature values, the temperature difference was calculated, and then the mean value $\Delta T_{\text {mean }}$ of this 20 differences were obtained (eqn. 2).

$$
\Delta T_{\text {mean }}=\frac{1}{20} \sum_{n=1}^{n=20} \Delta T_{i}
$$
sample.

where $\Delta T_{i}$ denote the temperature difference for 20 pairs of corresponding points on each side of the

The optimization procedure implemented in MATLAB ${ }^{\circledR}$ calculated thermal conductivity $\lambda$ in the iterative procedure by minimizing $\Delta T_{\text {mean }}$ down to the satisfactory value (Table 1 ).

Table 1. Results for $\lambda$ iterations, $\Delta T_{\text {mean }}$ is an error between the measurement and simulation results

\begin{tabular}{|l|l|l|l|l|l|}
\hline Iteration & $\lambda,[W /(m \cdot K)]$ & $\Delta T_{\text {mean },[K]}$ & Iteration & $\lambda,[W /(m \cdot K)]$ & $\Delta T_{\text {mean, }}[K]$ \\
\hline 1 & 381.966 & 7.68163 & 17 & 0.280034 & 0.323765 \\
\hline 2 & 618.034 & 7.68567 & 18 & 0.17307 & 1.76171 \\
\hline 3 & 236.068 & 7.6751 & 19 & 0.304711 & 0.666579 \\
\hline 4 & 145.898 & 7.66455 & 20 & 0.258922 & 0.00126095 \\
\hline 5 & 90.1699 & 7.64751 & 21 & 0.22613 & 0.576851 \\
\hline 6 & 55.7281 & 7.62001 & 22 & 0.256936 & 0.0335257 \\
\hline 7 & 34.4419 & 7.57573 & 23 & 0.263881 & 0.0779832 \\
\hline 8 & 21.2862 & 7.50465 & 24 & 0.259708 & 0.0114241 \\
\hline 9 & 13.1556 & 7.39107 & 25 & 0.258701 & 0.00483619 \\
\hline 10 & 8.13062 & 7.21097 & 26 & 0.259091 & 0.00147051 \\
\hline 11 & 5.0250 & 6.92878 & 27 & 0.258993 & 0.000113143 \\
\hline 12 & 3.10562 & 6.4948 & 28 & 0.259003 & $4.84886 \mathrm{e}-005$ \\
\hline 13 & 1.91938 & 5.86137 & 29 & 0.259023 & 0.000371728 \\
\hline 14 & 1.18624 & 4.96402 & 30 & 0.259002 & $3.23258 \mathrm{e}-005$ \\
\hline 15 & 0.733137 & 3.735 & 31 & 0.258999 & $1.6163 \mathrm{e}-005$ \\
\hline 16 & 0.453104 & 2.16517 & 32 & 0.2590 & 0 \\
\hline
\end{tabular}

The inverse thermal problem has been successfully solved for steady state conditions, confirming that the proposed approach is a good tool to evaluate the thermal parameters of the new textile materials. The research was splitted in two parts. After the first preliminary investigations in which the concept was verified for the 
homogenous material (Table 1), the 3-layer sample imitating the textile material with different porosity described above was takes for the experiment. The temperature distribution on both sides of the sample was registered by the thermovision camera. Three areas of interest were chosen, one with holes in the external and middle layer, the second with single holed plate, and the third one without any hole (Fig. 2). For all zones, so-called effective thermal conductivity coefficient was evaluated. The experiments were carried out for the sample presented as in Fig. 2. The aluminium foil was placed in the chosen areas in between two Teflon plates to imitate the electrically conductive textile.

Finally, six different material compositions have been obtained:

1. plate without holes - plate with holes - plate with holes,

2. plate without holes - Al foil - plate with holes - plate with holes,

3. plate without holes - plate with holes - plate without holes,

4. plate without holes - Al foil - plate with holes - plate without holes,

5. plate without holes - plate without holes - plate without holes,

6. plate without holes - Al foil - plate without holes - plate without holes.

Table 2. Optimisation results for 3-layer material

\begin{tabular}{|l|l|l|}
\hline \multicolumn{2}{|c|}{ Material composition } & $\lambda[\mathrm{W} /(\mathrm{m} \cdot \mathrm{K})]$ \\
\hline 1 & plate without holes - plate with holes - plate with holes & 0,212 \\
\hline 2 & plate without holes - Al foil - plate with holes - plate with holes & 0,232 \\
\hline 3 & plate without holes - plate with holes - plate without holes & 0,264 \\
\hline 4 & plate without holes - Al foil - plate with holes - plate without holes & 0,284 \\
\hline 5 & plate without holes - plate without holes - plate without holes & 0,302 \\
\hline 6 & plate without holes - Al foil - plate without holes - plate without holes & 0,318 \\
\hline
\end{tabular}

In this way, six different textile materials were imitated, including the nonwoven with metal wires for increasing thermal and electrical conductivity. The obtained results were quite satisfacting (Table 2). As it was expected, the areas with the metal foils have the higher value of the thermal conductivity, as well as the solid materials without or with the small porosity (without holes). The air in the textile material can decrease the thermal conductivity by more than $10 \%$. Finally in this research, the nonwoven with and without chase-change implants (PCM) was measured using thermovision camera (Fig. 6). The optimization procedure to get the thermal conductivity runs in the way as before, however up to now we do not know the exact value of the thermal conductivity measured using other reference methods.
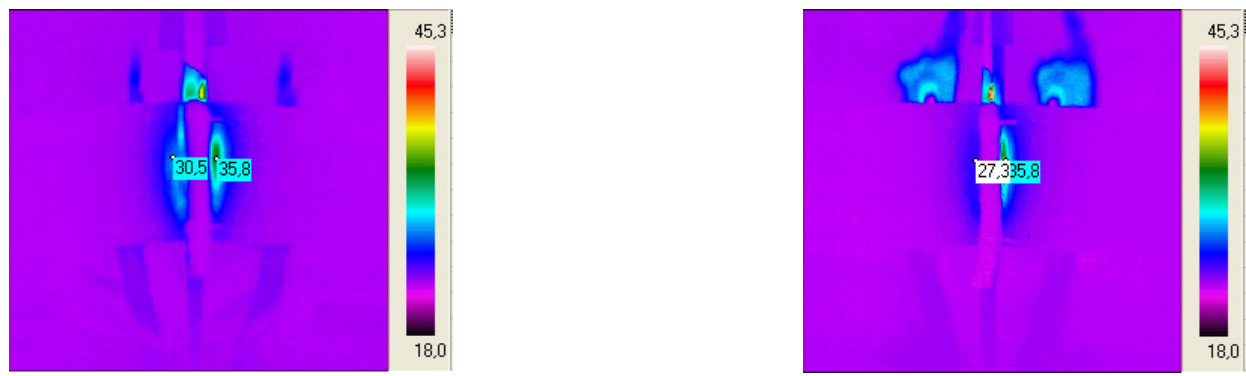

Fig.6. Thermal images of nonwoven without PCM and nonwoven with PCM at 355s of heating

\section{Conclusion}

A new method for evaluating the thermal conductivity for smart textiles has been developed. It is based on thermovision measurements of temperature simultaneously on both sides of the material during heating or cooling process. Because the process is dynamic, it is be possible to calculate the thermal capacity, what is planed in the next step of this research. The presented method is very sensitive to the boundary conditions and the input power agreements in calculations and experiments. The future investigations will try to make the method more independent from it and more applications for smart textiles will be performed to show its useness.

\section{REFERENCES}

[1] M. Michalak, B. Więcek, I. Krucińska, M.Lis: "Thermal Barrier Properties of Nonwovens Multilayer Structures Investigated by Infrared Thermography”. VII ${ }^{\text {th }}$ Quantitative Infrared Thermography - QIRT 2004, Brussels, Belgium, 5-8 July, 2004.

[2] M. Michalak, B. Więcek, I. Krucińska, Iwona Kubsz. Modelling and investigation of smart nonwovens with thermostabilization. 1st Aachen-Dresden International Textile Conference, Nov. 28-29, Aachen, 2007, on CD 
[3] M. Michalak, B. Więcek, I. Krucińska, M. Kaczmarek. „New Infrared Thermography Method for Investigation of Heat Transport in Nonwovens". VII International Conference ArchTex-2005, HIGH TECHNOLOGIES IN TEXTILES. Poland, Cracow, September 18 - 20 2005, pp. 13 -18.

[4] M. Michalak, B. Więcek, I. Krucińska M. Felczak "The Thermal Wave Method for Investigations of Textile Properties." VIth Quantitative InfraRed Thermography 6 - QIRT'2006.

[5] M. Michalak, B. Więcek, I. Krucińska, M.Felczak. Metoda fali cieplnej i luster podczerwieni do badania właściwości cieplnych płaskich materiałów włókienniczych. V Krajowa Konferencja TTP-2006, Ustroń, 1617 listopada 2006, s.355-360.

[6] M. Michalak, B. Więcek. Pomiary właściwości cieplnych płaskich wyrobów włóknistych metoda bezkontaktową. XXXIX Międzyuczelniana Konferencja Metrologów, Łódź, 24-26 września 2007, CD

[7] M. Michalak. B. Więcek. Estimating Thermal Properties of Flat Products by a New Non-contact Method. Fibres\&Textiles In Eastern Europe, vol.x, Nr, 2008, (accepted for publishing) 
http://dx.doi.org/10.21611/qirt.2008.11_04_05 